\title{
Fuzzy Comprehensive Model of Quantitative Evaluation of College Student Party Members' Evaluation Indexes
}

\author{
Guoming Jian ${ }^{1, ~ *, ~ C u i d a n ~ C h e n ~}{ }^{2}$ \\ ${ }^{1}$ School of Mathematics and Statistics, Shaoguan University, Shaoguan, China \\ ${ }^{2}$ School of Mathematical Sciences, South China Normal University, Guangzhou, China \\ Email address: \\ 527775876@qq.com (Guoming Jian) \\ ${ }^{*}$ Corresponding author
}

To cite this article:

Guoming Jian, Cuidan Chen. Fuzzy Comprehensive Model of Quantitative Evaluation of College Student Party Members' Evaluation Indexes. International Journal of Management and Fuzzy Systems. Vol. 4, No. 3, 2018, pp. 57-62. doi: 10.11648/j.ijmfs.20180403.14

Received: September 16, 2018; Accepted: November 7, 2018; Published: December 3, 2018

\begin{abstract}
With the rapid development of education, the number of college student party members has risen due to the expansion of university enrollment. However, the quality curve of college student party members is declining. They have a series of problems in their personal motivation and leading role. Constructing the evaluation indexes and quantitative assessment system for college students are not only the inevitable requirement for the Party Central Committee to improve the quality of party members, but also the necessary means to establish and improve the quality and quantity system for college students. This paper sets the five aspects of the political quality, daily performance, learning ability, work ability and innovation ability of college student party members as the first-level evaluation indexes, and adopts five principles such as the principle of directional assessment, the combination of qualitative and quantitative assessment principle, comprehensive principle, operability principle, diversity and multi-level principle. Each first-level evaluation index is refined into several secondary evaluation indexes. Through using the variation coefficient method, double weight method, parameter classification method and the like, we've given the specific steps to establish this fuzzy comprehensive model of the quantitative evaluation of college student party members' evaluation indexes so as to evaluate the overall quality of college student party members. Finally, an example is given to verify the rationality and accuracy of the proposed model.
\end{abstract}

Keywords: College Student Party Members, Evaluation Indexes, Quantitative Assessment, Fuzzy Comprehensive Model

\section{Introduction}

The key base for cultivating members of the Communist Party of China (CPC) is the university campus. In order to promote the quality development of the CPC members, it is necessary for us to start with the action from college student party members. To promote the development of the college student party members' quality, we can play the power of example and select the outstanding party members as the model representatives to let other party members learn from the example, and thus promote the healthy development of the quality of college student party members. In this regard, in order to make the power of the example truly reflected in the group of the college student party members, it is necessary to comprehensively assess and evaluate the overall quality of the college student party members. This paper is devoted to exploring and researching a quantitative model for comprehensive evaluation of college student party members' comprehensive quality, and establishing an evaluation indexes model for assessing the comprehensive quality of college student party members, and finally quantifying it.

Establishing the management system of the party members' party education among college student party members, perfecting the party membership quantitative evaluation indexes system, and innovating the education management mode of college student party members, as well as improving the quality and quality of college party members, have become an important content and goal of party building in colleges and universities. According to the directional assessment principle [1] of the evaluation indexes and quantitative assessment of college student party members, the principle of combination of qualitative and quantitative [2], the comprehensive principle, the operability 
principle, as well as the diversification and multi-level principle, etc., we decompose the college student party members' evaluation indexes into a two-level index system to establish a fuzzy comprehensive evaluation model of college student party members' evaluation indexes and quantitative assessment and show the results of comprehensive evaluation of college student party members. After establishing such an evaluation model, we can effectively and reasonably evaluate the overall quality of the college party members in the future.

The structure of this paper is organized as follows: in the next section, we present the main principles of evaluation indexes and quantitative assessment system which we have followed in this article. In the section 3, we analyze the evaluation indexes of college student party members that should be included in the assessment, and establish the evaluation indexes system for college student party members. In the section 4, we have showed the concrete steps to establish a fuzzy comprehensive model of quantitative evaluation of college student party members' evaluation indexes. In the section 5, we solve the model that we have established and report the results with the example that is given to support the rationality and accuracy of the proposed model. In the section 6 , we get some relevant conclusions from the fuzzy comprehensive model of quantitative evaluation of college student party members' evaluation indexes. Finally, the last two sections are acknowledgements and references respectively.

\section{The Main Principles of Evaluation Index and Quantitative Assessment System}

\subsection{Directional Assessment Principle}

Constructing the evaluation indexes and quantitative assessment system for college student party members, we must consistently adhere to the party's guiding ideology, take the party constitution as the criterion, adhere to the basic conditions for party members' development and the party members' rights as well as the obligations, and always maintain the party members' advanced and purity.

\subsection{The Assessment Principle of Combining Qualitative and Quantitative}

To achieve the fairness and justice in the assessment, on the one hand, it is necessary to strictly and quantitatively assess the objective conditions that for the development of college party members should have, namely" hard indexes", such as party grades, age of admission, academic achievements, awards, etc. Otherwise, the scores are not fair enough, and that may cause false results. On the other hand, "soft indexes" such as ideological and political quality, moral quality, and motivation for joining the party, which are difficult to quantify, should be observed and studied for a long time observation. Through the combination of the above two aspects to achieve the purpose of combining qualitative assessment with quantitative assessment.

\subsection{Comprehensive Principle}

To effectively reflect the evaluation results, the comprehensiveness of the evaluation indexes must be achieved. The comprehensiveness of the evaluation indexes refers to whether the evaluation indexes summarized include the most important index factors that can be used to evaluate the overall quality of the college student party members.

\subsection{Operability Principle}

To study and construct the evaluation indexes and quantitative assessment system for college student party members, it is necessary to ensure that the evaluation indexes and quantitative assessment system should be operational and have practical contents. Any "hard indexes" should be quantified, and the "soft indexes" should be quantified by a long-term observation of the daily behavior of the evaluated party members and finally to achieve the quantification of "soft indexes".

\subsection{Diversity and Multi-level Principle}

When researching and constructing the evaluation indexes and quantitative assessment system for college students, it is necessary to analyze the opinions of review students and listen to the opinions of the review teachers. In addition, it is necessary to combine the opinions of the party members within the party with the opinions of non-party persons who are in close contact with the evaluated party member, so as to follow the diversity and multi-level principle to assess the college student party members.

\section{Analysis on the Quantitative Assessment of College Student Party Members' Evaluation Indexes}

The comprehensive quality evaluation indexes of college student party members involve the political quality of college student party members [3], the daily performance, the learning ability, the work ability, the innovation ability and so on. There is some ambiguity among them, and it is often difficult for us to objectively evaluate the above aspects' comprehensive performance, therefore, the fuzzy comprehensive evaluation model is used to solve this problem. In the actual assessment of the comprehensive quality of college student party members, its assessment and evaluation indexes generally include two aspects, namely "hard indexes" and "soft indexes". "Hard indexes", namely explicit indexes, include academic achievements, awards, disciplinary behaviors and the like of the student members. Obviously, the "hard indexes" are very easy to quantify and must be quantified to reflect the fairness and impartiality of the assessment. If we do not quantify the evaluation indexes, relying solely on feelings to judge, there will be a phenomenon based on impression evaluation, which runs 
counter to fairness and justice. "Soft indexes", namely hidden indexes, include the aspects of political quality, ideological and moral, daily performance, motivation of joining the party, etc. among the student party members. Because such indexes are difficult to grasp, they brought more difficulty to the assessment work. After analyzing, this paper followed the principle of combining qualitative and quantitative, etc. and then built the structure of the evaluation indexes system for college student party members. [3, 4]. As it shown in Figure 1.

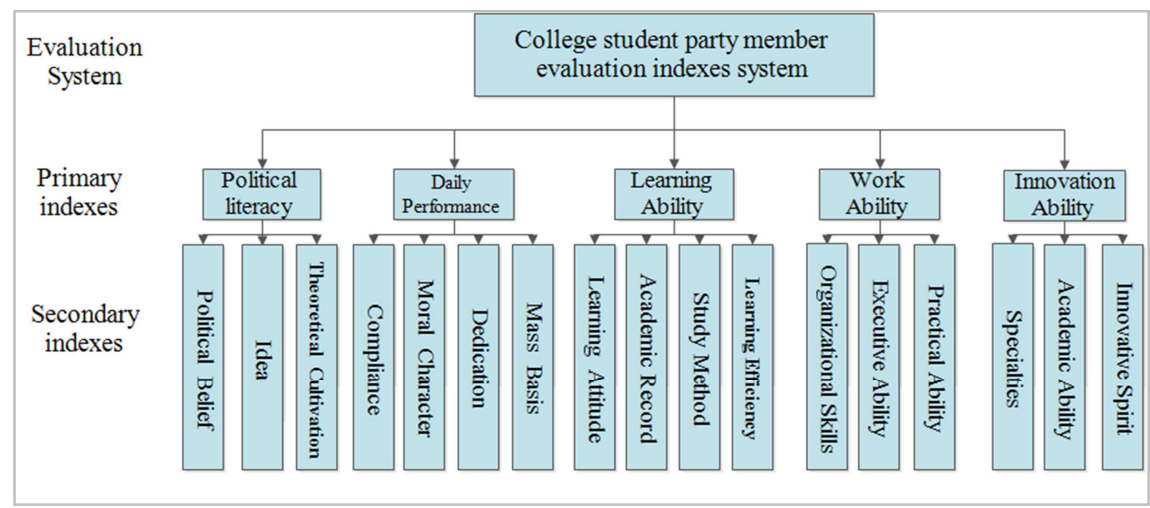

Figure 1. Structure of the evaluation indexes system for college student party members.

\section{Fuzzy Comprehensive Model for Quantitative Evaluation Indexes}

This paper uses the theory of fuzzy mathematics to quantify and evaluate the evaluation indexes of the college students' comprehensive quality. The coefficient of variation method with objective assignment characteristics is used to determine the weight of each evaluation index so as to eliminate the influence of the subjective factors. The weighted average method is used in this paper to analyze the results of fuzzy comprehensive evaluation. Mean completer method makes the problem of data loss of data solved by assigning reasonable weights to each evaluation index. The composition of the fuzzy comprehensive model [5] includes the evaluation indexes set $U$, evaluation level domain $V$, and fuzzy relation matrix $R$. Applying the relevant theory of fuzzy mathematics to the research on the evaluation indexes and quantitative assessment system of college student party members, establishing the single-layer model of fuzzy comprehensive evaluation model for evaluating the comprehensive quality of college student party members by using secondary indexes. The construction process is summarized as follows:

\subsection{Model Assumptions}

(1) Assume that the established assessment team score objectively and the team consisting of a $N$ - person team including classmates, counselors, teachers, and class teachers;

(2) Assume that the scores of the evaluated party members given by the selected $\mathrm{N}$-person team is representative;

(3) Assume that all data is reasonable and scientific;

(4) Assume that the collected questionnaires reflect the true thinking of the members of each assessment team;

(5) Assume that the content of the questionnaire is representative.

\subsection{Indexes Division and Evaluation Level Determination}

The comprehensive quality of college student party members is divided into 17 secondary indexes based on this 5 primary indexes: political literacy, daily performance, learning ability, work ability and innovation ability. Then we can determine the evaluation indexes set $U$ of college student party members, and set the evaluation level domain $V$ as follows:

$$
\begin{aligned}
& U=\left\{u_{1}, u_{2}, \ldots, u_{5}\right\} \\
& V=\left\{v_{1}, v_{2}, \ldots, v_{5}\right\}
\end{aligned}
$$

Among them, $u_{i}=\left\{u_{i j}\right\}, i, j=1, \cdots, 5$ are the number of each secondary indexes under the primary indexes, and $v_{i}(i=1,2, \cdots, 5)$ represent the evaluation words 'excellent', 'good', 'medium', 'general', 'poor' respectively.

\subsection{Determination of Membership Function}

The indexes are classified qualitatively by statistical method, and they are calculated quantitatively by membership function. This paper obtains statistics through statistics on the actual questionnaire data, and uses these data to determine the membership function. In a second-level college which the number of students is 81 , we select $25 \%$ of that denoted $N$-person evaluation people to collect and count the statistics which get from the designed evaluation questionnaires filled by the $L$-student party members. The $N$ person evaluation team (where $N=20$, the same below) gives the votes for each evaluation index of the college student party members. The custom membership function is defined as follows:

$$
c_{i j}=\frac{\sum_{k=1}^{L}\left(e_{i j}\right)_{k}}{L}
$$

Among it, $c_{i j}$ indicates the average number of votes for the 
$j$-th evaluation level of the $i$-th evaluation factor of the $k$-th members of the $L$ college student party members given by the $N$-person evaluation team. The same below. $\left(e_{i j}\right)_{k}$ indicates the number of votes of the $j$-th evaluation level of the $i$-th evaluation factor of the $k$-th party member. Each value $c_{i j}$ together constitutes a membership matrix as follows:

$$
C=\left(c_{i j}\right)_{17 \times 5}
$$

Table 1 shows the data obtained after collecting the questionnaire with processing.

Table 1. Evaluation data of the evaluation team on the indexes of party members.

\begin{tabular}{|c|c|c|c|c|c|c|}
\hline \multirow{2}{*}{ Primary Indexes } & \multirow{2}{*}{ Secondary Indexes } & \multicolumn{5}{|c|}{ Evaluation level } \\
\hline & & Excellent & Good & Medium & General & Poor \\
\hline \multirow{3}{*}{ Political literacy $u_{1}$} & $u_{11}$ & 1 & 14 & 5 & 0 & 0 \\
\hline & $u_{12}$ & 1 & 7 & 9 & 2 & 1 \\
\hline & $u_{13}$ & 1 & 6 & 12 & 1 & 0 \\
\hline \multirow{4}{*}{ Daily Performance $u_{2}$} & $u_{21}$ & 2 & 6 & 9 & 2 & 1 \\
\hline & $u_{22}$ & 2 & 4 & 7 & 5 & 2 \\
\hline & $u_{23}$ & 3 & 6 & 7 & 2 & 2 \\
\hline & $u_{24}$ & 2 & 5 & 9 & 2 & 2 \\
\hline \multirow{4}{*}{ Learning Ability $u_{3}$} & $u_{31}$ & 3 & 11 & 3 & 2 & 1 \\
\hline & $u_{32}$ & 5 & 9 & 4 & 1 & 1 \\
\hline & $u_{33}$ & 2 & 13 & 4 & 1 & 0 \\
\hline & $u_{34}$ & 1 & 4 & 8 & 5 & 2 \\
\hline \multirow{3}{*}{ Work Ability $u_{4}$} & $u_{41}$ & 2 & 4 & 10 & 3 & 1 \\
\hline & $u_{42}$ & 4 & 7 & 6 & 2 & 1 \\
\hline & $u_{43}$ & 2 & 6 & 8 & 3 & 1 \\
\hline \multirow{3}{*}{$\begin{array}{l}\text { Innovation Ability } \\
u_{5}\end{array}$} & $u_{51}$ & 3 & 7 & 8 & 2 & 0 \\
\hline & $u_{52}$ & 2 & 4 & 5 & 6 & 3 \\
\hline & $u_{53}$ & 4 & 7 & 6 & 2 & 1 \\
\hline
\end{tabular}

\subsection{Building a Fuzzy Relation Matrix}

$$
r_{i j}=\frac{c_{i j}}{\sum_{j=1}^{5} c_{i j}} i=1,2, \cdots, 17: j=1,2, \cdots, 5
$$

Among it, $r_{i j}$ represents the proportion of the number of votes of the $j$-th evaluation level of the $i$-th evaluation index in the same evaluation indexes of the total number of votes. After normalizing $r_{i j}$, we have the formula as follows:

$$
x_{i j}=\frac{r_{i j}-r_{\min (j)}}{r_{\max (j)}-r_{\min (j)}}
$$

Among it,

$$
\begin{gathered}
r_{\max (j)}=\max _{i}\left\{r_{i j}\right\}, \\
r_{\min (j)}=\min _{i}\left\{r_{i j}\right\}, \\
(i=1,2, \cdots, 17 ; j=1,2, \cdots, 5)
\end{gathered}
$$

After the above processing, the $r_{i j}$ in the indexes is converted into a fuzzy relationship $x_{i j}$ of the standard single factor evaluation index for each evaluation level, its value falls in the interval $[0,1]$. All the values $x_{i j}$ together constitute a fuzzy relation matrix $R$ of the evaluation indexes set to the evaluation level as follows:

$$
\begin{gathered}
\mathrm{R}=\left(x_{i j}\right)_{m \times n}=\left[\begin{array}{cccc}
x_{11} & x_{12} & \cdots & x_{1 n} \\
x_{21} & x_{22} & \cdots & x_{2 n} \\
\vdots & \vdots & \ddots & \vdots \\
x_{m 1} & x_{m 2} & \cdots & x_{m n}
\end{array}\right], \\
(i=1,2, \cdots, m, j=1,2, n, m=17, n=5
\end{gathered}
$$

By using MATLAB mathematical software, the fuzzy relation matrix $\bar{R}$ obtained in this study is shown as follows:

$$
\bar{R}=\left[\begin{array}{lllll}
0.05 & 0.70 & 0.25 & 0.00 & 0.00 \\
0.05 & 0.35 & 0.45 & 0.10 & 0.05 \\
0.05 & 0.30 & 0.60 & 0.05 & 0.00 \\
0.10 & 0.30 & 0.45 & 0.10 & 0.05 \\
0.10 & 0.20 & 0.35 & 0.25 & 0.10 \\
0.15 & 0.30 & 0.35 & 0.10 & 0.10 \\
0.10 & 0.25 & 0.45 & 0.10 & 0.10 \\
0.15 & 0.55 & 0.15 & 0.10 & 0.05 \\
0.25 & 0.45 & 0.20 & 0.05 & 0.05 \\
0.10 & 0.65 & 0.20 & 0.05 & 0.00 \\
0.05 & 0.20 & 0.40 & 0.25 & 0.10 \\
0.10 & 0.20 & 0.50 & 0.15 & 0.05 \\
0.20 & 0.35 & 0.30 & 0.10 & 0.05 \\
0.10 & 0.30 & 0.40 & 0.15 & 0.05 \\
0.15 & 0.35 & 0.40 & 0.10 & 0.00 \\
0.10 & 0.20 & 0.25 & 0.30 & 0.15 \\
0.20 & 0.35 & 0.30 & 0.10 & 0.05
\end{array}\right]
$$

\subsection{Weight Vector Calculation}

In order to avoid the influence of human subjective factors, combined with the composition of fuzzy relation matrix, this paper uses the coefficient of variation method which has objective assignment characteristics to determine the weight of each evaluation index. The specific steps are as follows:

Step 1. Calculate the mean value $\bar{x}_{l}$,

$$
\bar{x}_{\iota}=\frac{1}{5} \sum_{j=1}^{5} x_{i j}, i=1,2, \cdots, 17
$$

Step 2. Calculate the standard deviation $\delta_{i}$, 


$$
\delta_{i}=\sqrt{\frac{1}{n} \sum_{j=1}^{5}\left(x_{i j}-\overline{x_{l}}\right)^{2}},(n=5, i=1,2, \cdots, 17)
$$

Step 3. The coefficient of variation is calculated as follows:

$$
v_{i}=\frac{\delta_{i}}{\bar{x}_{\imath}} i=1,2, \cdots, n_{i}
$$

Among it, $v_{i}$ is the standard deviation coefficient of the $i$ th index, which is the coefficient of variation [6]; $\delta_{i}$ is the standard deviation of the $i$-th index; $\overline{x_{l}}$ is the average value of the $i$-th index.

Step4. Calculate the weight $w_{i}$ of each evaluation index from the coefficient of variation, and the calculation formula is as follows:

$$
w_{i}=\frac{v_{i}}{\sum_{i=1}^{n} v_{i}}
$$

According to the above steps, the weight vector can be obtained as follows:

$$
W=\left(w_{1}, w_{2}, \cdots, w_{i}\right)
$$

Among it, $w_{i}$ is the weight value of each index and satisfies

$$
0 \leq w_{i} \leq 1, \sum_{i=1}^{m} w_{i}=1, i=1,2, \cdots, 17 .
$$

By using $M A T L A B$ mathematical software, the weight vector $W$ calculated by MATLAB mathematical software as follows:

$$
W=(0.10,0.07,0.09,0.06,0.04,0.04,0.05,0.07,0.06,0.03,0.04)
$$

\subsection{The Result Vector}

According to the survey statistics as well as the determination of the fuzzy relation matrix in 4.4, we can obtain the fuzzy relationship matrix $R$ of each evaluated college student party member. Finally, synthesizing $W$ and $R$ to obtain the fuzzy comprehensive evaluation result vector of each college student party members as it shown as follows:

$$
B=W \circ R=\left(w_{1}, w_{2}, \cdots, w_{17}\right)^{\circ}\left[\begin{array}{cccc}
r_{11} & r_{12} & \cdots & r_{1 l} \\
r_{21} & r_{22} & \cdots & r_{2 l} \\
\vdots & \vdots & \ddots & \cdots \\
r_{17,1} & r_{17,2} & \cdots & r_{17, l}
\end{array}\right]
$$

Among it,

$$
B=\left(b_{1}, b_{2}, \cdots, b_{5}\right)
$$

\section{Solving the Evaluation Model of Party Members' Evaluation Indexes}

We select the evaluation synthesis operator firstly, here we use the weighted average type of synthetic operator model.
The operator calculation formula is shown below:

$$
b_{j}=\sum_{i=1}^{m}\left(w_{i} \cdot r_{i j}\right), 1 \leq i \leq 17, j=1,2, \cdots, l
$$

This synthetic operator model combines the weights of each evaluation index, and reflects the overall comprehensive quality characteristics of the evaluated college student party members in the whole. Therefore, the final evaluation result $B$ of each evaluated college student party member can be obtained. According to the principle of maximum membership, each member of the evaluated college student party member can be classified into the corresponding evaluation level.

In addition, in order to make full use of the comprehensive evaluation information to obtain a comprehensive evaluation value, this paper uses the double weight method [7], put 'excellent', 'good', 'medium', 'general', 'poor' in order, taking 5 to 1 points in descending order of assignment rules, then we can obtain the quantitative score $Q$ of the student party members' quantitative assessment:

$$
Q=S \circ B=5 * b_{1}+4 * b_{2}+3 * b_{3}+2 * b_{4}+1 * b_{5}
$$

Among it, $S=\left(\begin{array}{llll}5 & 4 & 3 & 2\end{array}\right)$ is the assignment vector for each evaluation level. The score of each evaluated college student party member is calculated, and the final evaluation value $Q$ is obtained. These evaluation values are sorted to obtain the ranking of each evaluated college student party member.

Instance verification: According to the result of the questionnaire survey about the comprehensive quality evaluation of the college student party members conducted by a college student party member, the data obtained as follows:

Table 2. The result of survey questionnaire on the comprehensive quality evaluation of college student party members.

\begin{tabular}{lll}
\hline Options & contents & Number of votes \\
\hline 1 & Excellent & 2 \\
2 & Good & 8 \\
3 & Medium & 7 \\
4 & General & 2 \\
5 & Poor & 1 \\
\hline
\end{tabular}

Among them, the number of votes in the table is the average number of votes for each party member under the 17 secondary indexes. From the data in Table 2, the ratios evaluated as 'excellent', 'good', 'medium', 'general', and 'poor' are: 0.10 .40 .350 .10 .05 . That is mean the actually result questionnaire survey is as follows:

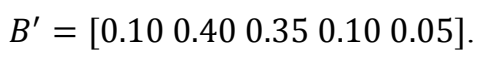

And the comprehensive quality evaluation index of party members is:

$\mathrm{Q}^{\prime}=5 * 0.10+4 * 0.40+3 * 0.35+2 * 0.1+1 * 0.05=$ 3.40 .

The ratio calculated by establishing a fuzzy comprehensive 
evaluation system is:

$$
B=\left[\begin{array}{llll}
0.11 & 0.39 & 0.35 & 0.010 .04
\end{array}\right]
$$

The comprehensive quality evaluation index of party members is $Q=3.42$. Comparing the two results above, the error between them is only $0.006 \%$, so the rationality and accuracy of the fuzzy comprehensive evaluation system and comprehensive quality evaluation model established in this paper are illustrated [8].

\section{Conclusion}

Using the coefficient of variation method to determine the weight vector in fuzzy comprehensive evaluation method to establish the evaluation model of college student party members can improve the scientificity and credibility of the weight distribution for the evaluation indexes and make the evaluation results more reasonable $[9,10]$. This model has wide applicability and adaptability, and it is highly portable. It is suitable for the evaluation indexes and quantitative assessment of college student party members, the evaluation of students' comprehensive quality, for the evaluation of teachers' teaching quality and even for the evaluation of the employee in many enterprises and departments, etc. Using MATLAB mathematical software for programming and calculating makes the model solving process become easier and faster. However, the solution of the model may be affected by the actual situation to a certain extent. In terms of model checking, this model is reasonable. Moreover, it is noted that the model can be improved into a two-layer fuzzy comprehensive evaluation model. It is possible to establish a comprehensive evaluation vector for each secondary index with each level of evaluation, and then let each primary index establish a comprehensive evaluation vector for each evaluation level. In addition, if the evaluations of students, teachers, class teachers, and counselors are given different weights, the model can be analogized to the third-level evaluation model.

\section{Acknowledgements}

This work is supported by the Undergraduate Teaching
Quality and Reform Project of Guangdong Universities under Grant CEHL [2014]97.

\section{References}

[1] Yan Zhengying, Ye Guiqing. Study on the Quantitative Evaluation Indexes System for the Quality Control of College Student Party Members in the New Situation [J]. Journal of Hubei Correspondence University, 2015, 28(21): 44-51.

[2] Chen Jiacong, Zuo Zhifu, et al. The basic principles and methods of constructing the evaluation system of college student party members[J]. Journal of Guangzhou University of Traditional Chinese Medicine, 2011, 19(6)63-64.

[3] Dong Wenbo, Research Report on Establishing Quantitative Evaluation Model of College Student Party Members Development [J]. Journal of Hubei Automotive Industries Institute, 2012, 32(2): 108-113.

[4] Zheng Zidong et al. Construction and application of the evaluation index system for the development of college party members [J], Moral Education Research, 2013(15): 87-93.

[5] Jin Xuelian, Lan Jie. Application of Fuzzy Comprehensive Evaluation in College Students' Consumption Level[J]. Journal of Liaoning University of Technology (Natural Science Edition), 2011, 31(6)405-408.

[6] Chen Li, Zhang Chaoyuan. Application of Efficacy Coefficient Method in Comprehensive Evaluation of Wenchuan Earthquake Disaster [J]. Journal of Anhui Agricultural Sciences, 2012(10): 5730-5733.

[7] Zhao Xinghua. On the Application of "Double Right Law" in Wine Evaluation[J]. Brewing Science \& Technology, 2000(1): 103-105.

[8] Cheng Huaqin et al. Construction of Evaluation Index System for College Student Party Members [J], Student Work, 2012(4): 78-84.

[9] Liu Ruijiao et al. Research on the construction of quantitative evaluation index system for college students in science and engineering $[\mathrm{J}]$. Journal of Tianjin University of Commerce, 2010(6): 106-112.

[10] Wang Chuanxu et al. Emphasis on the Party-building work of college students from a strategic perspective [J]. China Higher Education Research, 2006 (3): 125-131. 